\title{
Comparison of the different controlling techniques for buck converter in LED application
}

\author{
Shwetha D.V., Lakshman Rao S. Paragond \\ Department of Electrical \& Electronics Engineering, Manipal Institute of Technology, Mahe, India
}

\begin{tabular}{|c|c|}
\hline Article Info & ABSTRACT \\
\hline Article history: & \multirow{6}{*}{$\begin{array}{l}\text { This paper recounts the design and construction of various controlling } \\
\text { techniques for buck converter. If the designed controller for any converter is } \\
\text { not proper which leads to high overshoot and steady state error, and its } \\
\text { dynamic response varies with changes in load, especially at high load current } \\
\text { conditions. The lead-lag controller for the converter is desgined using } \\
\text { classical control theory, Bode Plot technique is used to examine the stability } \\
\text { of the system.By using deravetive part of the PID controller on output signal } \\
\text { instead of voltage error signal,this combination of control technique reduces } \\
\text { the overshoot and settling time, and how the transient response will be } \\
\text { affected if deravetive controller is in the forward path. }\end{array}$} \\
\hline Received Jan 15, 2018 & \\
\hline Revised Sep 26, 2018 & \\
\hline Accepted Nov 23, 2018 & \\
\hline Keywords: & \\
\hline $\begin{array}{l}\text { Buck converter } \\
\text { LED application }\end{array}$ & \\
\hline
\end{tabular}

Copyright (C) 2019 Institute of Advanced Engineering and Science. All rights reserved.

\section{Corresponding Author:}

Shwetha D.V.,

Department of Electrical \& Electronics Engineering,

Manipal Institute of Technology, Mahe, India.

Email: shwethadvs@gmail.com

\section{INTRODUCTION}

Getting good transient response for the low and high frequency converters has been the main aim of the converter designers, because if there is a sudden increase in load current, the increased current need to be sourced by output capacitor, if the system response is low the system cannot respond quick enough to increase output supply current. This causes a sharp dip in the output voltage. The slowness of the system causes the voltage to take a long time to recover from the dip, increase the current to level of demand, and build back voltage to its specified level, this cause insufficient power supply to the some of the blocks in the system.

Different controlling techniques can be used to increase the Satatic and dynamic performance such as adpative control (current balancing on/off controll) [1],Linear quadratic-Gaussian and lead compensator [2],fractional order control [3],PID control [4], Particle swarm optimization-based PID controller [5], neural network [6].While designing a controller the designer should be more careful on placing the Zeros and Poles of the lead-lag controller to get good transient response [7]. Peak overshoot and rise time can be decreased by increasing the gain of the system at higher frequencies [8]. Steady state error can be improved by incraesing the gain of the system at lower frequencies, Lag compensator can be used to increase the gain of the system at lower frequencies. With the use of lead-lag values PID controller is designed, and that PID controller is configured into different configuration, by placing the derivative of the PID controller out of the forward path will prevent the impulses as a part of the control signal [9]. This paper tells How the transient response will be affected for the different configuration of the PID. Most of the above techniques are PID or modified PID type [11].

This paper gives different methods for constructing a PID controller on the basis of classical theory of control system using Bode plot technique. And also gives how the controller path will affect the system 
response. Care should be taken while designing a feedback path. How proportional, integral, derivative in the feedback path will affect the system response. Different configuration of control paths is compared.

This paper is structured as follows: started with (section 2) small signal modelling of the converter, (section 3) detailed design procedure for a design of lead-lag controller using Bode plot technique. (Section 4) Simulation results using MATLAB. (Section 5) Conclusion.

\section{METHOD}

Buck converter is step down chopper, it steps down the voltage from its input to output. It is a group of switched mode supply, mainly it consists of two semiconductor and one energy storage element, storage element may be a capacitor or inductor or the combination. Operation of the buck converter is current through the inductor to be controlled, this is done by using two switches. Main advantage of using Switch and diode is voltage drop will be zero during on condition and current flow will be zero during off, hence power loss during on and off condition will be zero, hence efficiency of the system will increase. Buck converters are used where the DC out put voltage needs to be lower than the dc input. During this process if there is increase in step current, the entire current increase will need to be sourced by output capacitor, if the system response is slow then system cant respond quickly enough to increase output supply current (due to poor transient response). this causes sharp dip in the output voltage, slowness of the system causes the voltage to take a long time to recover from the dip [10], [11].

\subsection{Buck converter design}

Converters will work in two modes

a. Continuous conduction

b. Discontinuous conduction

Continuous conduction mode is more advantageous then discontinuous conduction. Discontinuous mode is having disadvantage of high ripple at output voltage, high ripple current in the semiconductors, and high flux density in the inductor. Figure 1 shows the block diagram of the buck converter having a feedback loop. The converter mainly consists of a switch, diode and LC low-pass filter with nonlinearities such as inductor resistance, $R L$, and capacitor resistance, $R C$, are connected in series to the inductor and capacitor. Capacitor resistance Rc introduces a zero frequency in the transfer function. Table 1 shows buck converter specifications.

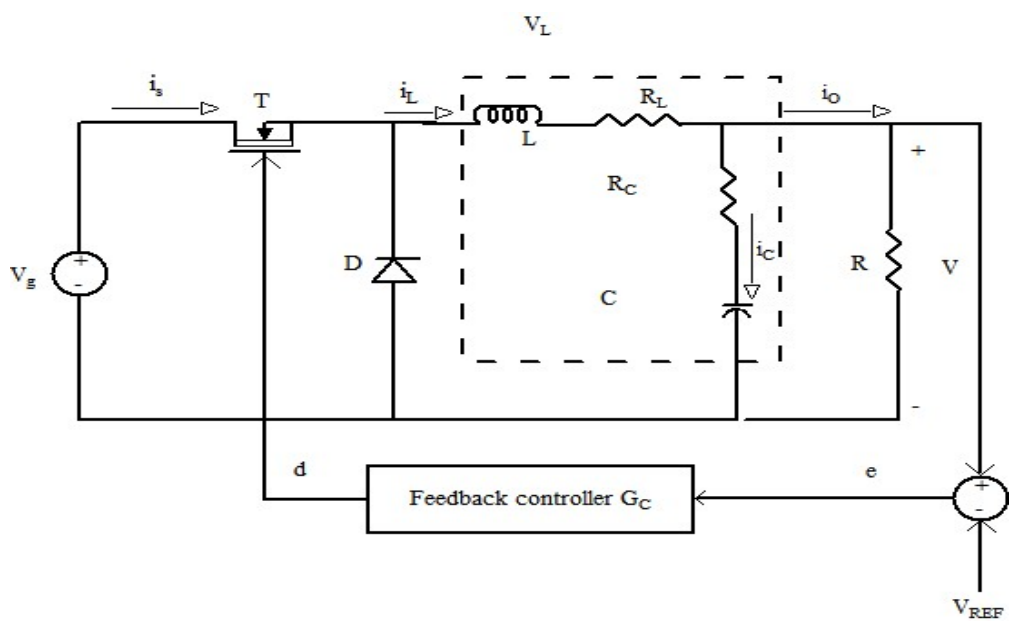

Figure 1. Closed loop buck converter

Large Signal modal:

Switch on

$$
\begin{aligned}
& V_{L}=V_{g}-I_{L} R_{L}-V \\
& I_{C}=I_{L}-V / R
\end{aligned}
$$


Switch off

$$
\begin{aligned}
& V_{L}=-\left(I_{L} R_{L}+V\right) \\
& I_{C}=I_{L}-V / R \\
& \frac{V}{V_{g}}=\frac{R D}{R_{L}-R}
\end{aligned}
$$

Small signal modal:

Switch on

$$
\begin{aligned}
& \mathrm{L} \frac{d\left(I+i_{L}\right)}{d t}=\left(\left(V_{g}+\hat{v}_{g}\right)-\left(I_{L}+\hat{\imath}_{L}\right) R_{L}-(V+\hat{v})\right)(D+\hat{d} t)+ \\
& \left(-\left(I_{L}+\hat{\imath}_{L}\right) \mathrm{R}-(V+\hat{v})+\left(\mathrm{D}^{\mathrm{l}}-\hat{d} t\right)\right. \\
& \mathrm{L} \frac{d\left(i_{L}\right)}{d t}=V_{g} \hat{d} t+\hat{v}_{g} D-\hat{\imath}_{L} R_{L}-\hat{v}(t)
\end{aligned}
$$

Switch Off

$$
\begin{aligned}
& \left.\left.\mathrm{C} \frac{d(V+\hat{v})}{d t}=(I+\hat{\imath}(t))-(V+\hat{v}) / \mathrm{R}\right)(D+\hat{d} t)+(I+\hat{\imath}(t))-(V+\hat{v}) / \mathrm{R}\right)\left(\mathrm{D}^{\mid}+\hat{d} t\right) \\
& \mathrm{C} \frac{d(V+\hat{v})}{d t}=\hat{\imath}(t)-v(t) / R
\end{aligned}
$$

\begin{tabular}{|c|c|c|}
\hline Parameter & Symbol & Value \\
\hline Load & $R$ & $4.4 \Omega$ \\
\hline Sensor Gain & $H(s)$ & 1 \\
\hline Sampling Period & Ts & $1 \mu \mathrm{s}$ \\
\hline Switching Frequency & Fs & $1 \mathrm{MHz}$ \\
\hline Reference Voltage & Vref & $2 \mathrm{~V}$ \\
\hline Input Voltage & Vin & $3.6 \mathrm{~V}$ \\
\hline Output Voltage & Vout & $2 \mathrm{v}$ \\
\hline Filter Capacitor & $\mathrm{C}$ & $4.6 \mu \mathrm{F}$ \\
\hline Filter Inductor & $\mathrm{L}$ & $4.6 \mu \mathrm{H}$ \\
\hline Resistance of Inductor & $R L$ & $504 \mathrm{~m} \Omega$ \\
\hline Resistance of Capacitor & $R C$ & 5 \\
\hline
\end{tabular}

Buck converter output to control function is:

$$
\frac{V_{o}(s)}{d}=\frac{V_{\text {in }}(S)\left(\frac{R}{R+R_{l}}\right)\left(R_{C} C S+1\right)}{C L\left(\frac{R+R_{C}}{R+R_{l}}+C\left(R \| R_{l}\right)+R_{C} C\right) S+1}
$$

Table 1. Buck converter specifications

\subsection{Controller design}

Figure 2 represents the bode plot of the open loop system before the compensation, Gm=inf, $\mathrm{Pm}=25.8^{\circ}(70.8 \mathrm{kHz})$, both gain margin and phase margin are positive, system is stable. The pole causes a phase margin of $25.8^{\circ}$ at a gaincross over frequency of 70 . 8kHz.It has less phase margin it should be improved to improve the transient response of the system. A compensator should be designed to get the higher gain at lower frequencies to improve the steady state response and higher gain at higher frequencies to improve the transient response and gain at the switching frequency should be unity for stable system. Phase margin should be in the range of $50^{\circ}$ to $60^{\circ}$ to meet the required transient response of the system.

$$
\text { Open loop Transfer Function }(\mathrm{TF})=\frac{7.606 \mathrm{e}-08 \mathrm{~s}+3.237}{1.988 \mathrm{e}-11 \mathrm{~s}^{\wedge} 2+3.097 \mathrm{e}-06 \mathrm{~s}+1}
$$

Bode diagram of Buck converter.

$\mathrm{Gm}=$ Gain margin

$\mathrm{Pm}=$ phase margin 


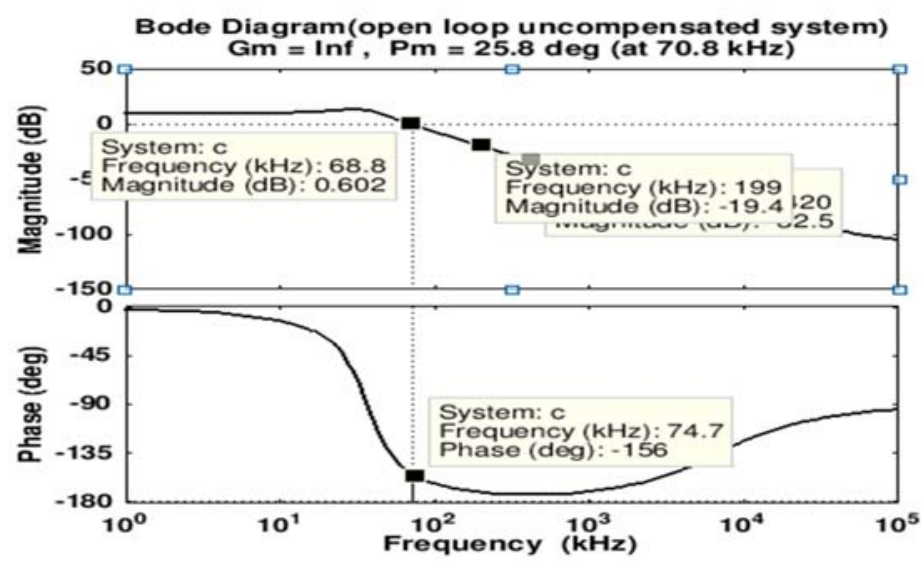

Figure 2. Bode plot of the buck converter before compensation

\subsection{Step response of the uncompensated system}

Peak overshoot $=57.6$, rise time $=2.56 e^{-06}$, Settling time $=4.96 e^{-05}$, ess $=0.764$.

In Figure 3 high Overshoot indicates an output exceeding its final steady-state value, which leads high distortion into the signal, distrotion will affect the damping, settling time, and rise time.

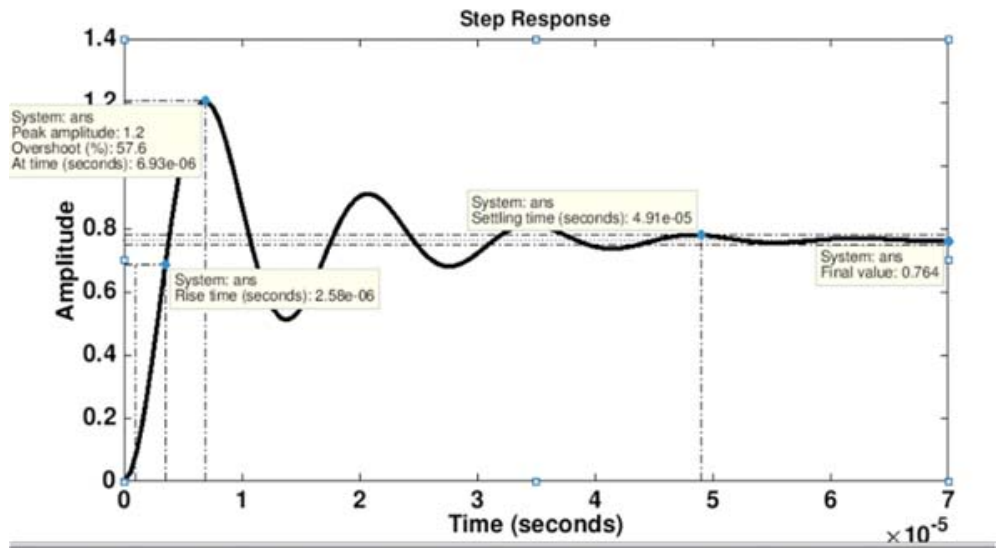

Figure 3. Step response of the system before compensation

Procedure for a lead-lag controller using Bode plot technique.

a. $\quad$ PID controller is designed using bode plot technique, based on lead-lag network. While designing pid controller pd should be designed first then pi should design otherwise pd will affect the steady state error.

b. Selection of zero in the compensator design causes the compensator to differentiate the error signal and it will increase the compensator gain at higher frequencies with a slop of $20 \mathrm{~dB}$.In practical systems gain will tend to zero at higher frequencies hence compensator should containehigh frequency poles. High frequency pole will attenuate the noise at the higher frequencies. If the gain of the system is high at switching frequency, then compensator will amplify the switching harmonics. With the increase in harmonics, loses in the system will increases, hence compensator should contain pole at a frequency less then the switching frequency.

$$
\text { Lead compensator }=G \operatorname{co} \frac{\left(1+\frac{S}{W z}\right)}{\left(1+\frac{S}{W p}\right)}
$$




$$
\mathrm{f}_{\mathrm{p}}=\mathrm{f}_{\mathrm{c}} * \sqrt{\frac{1+\sin \emptyset_{\mathrm{m}}}{1-\sin \emptyset_{\mathrm{m}}}}
$$

$W_{p}=$ Frequency at which lead compensator pole is placed.

$$
\begin{aligned}
& W_{p}=2 \pi f_{p} \\
& f_{z}=f_{c} * \sqrt{\frac{1-\sin \emptyset_{m}}{1+\sin \emptyset_{m}}}
\end{aligned}
$$

$W_{z}=$ Frequency at which lead compensator zero is placed.

$$
W_{z}=2 \pi f_{z}
$$

Frequency at which maximum phase occurs is $-\mathrm{fmax}=\sqrt{(\mathrm{fz} * \mathrm{fp})}$

If fmax is same as the loop gain cross over frequency fc, then there will be improvement in phase margin is high. To avoide changing in cross overfrequency, to improve the transient response compensator gain should be unity at the loop gain cross over frequency. The lead Compensator will decrease the rise time and setlling time. Since phase margin $\left(\emptyset_{m}\right)$ will affect the transient response, hence phase margin will be calculated based on the transient requirement. Peak overshoot and rise time will depend on the value of $Q$ (Quality factor).

$$
\emptyset_{m}=\sqrt{\frac{1+\sqrt{1+4 Q^{2}}}{2 Q^{2}}}
$$

Always for good transient response $\mathrm{Q}=1$, phase margin is inversely related to the $\mathrm{Q}$, as $\mathrm{Q}$ value is low phase margin will increase. Loop gain Gco is added to get the unity gain at the switching frequency. Figure 4 represents the transient response of the system after the Lead Compensation $\% \mathrm{Mp}=27.3$, $\operatorname{tr}=1.96 e^{-6}$, ess $=0.764$.

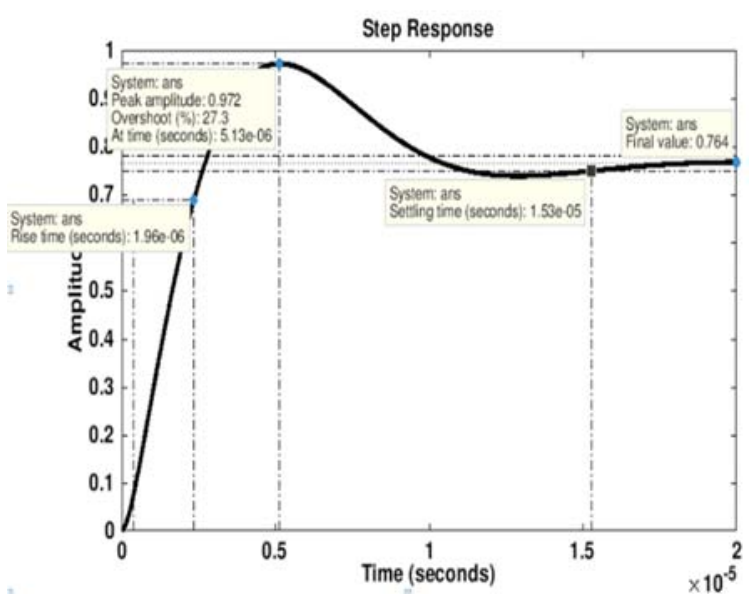

Figure 4. Step response of the system after lead compensation

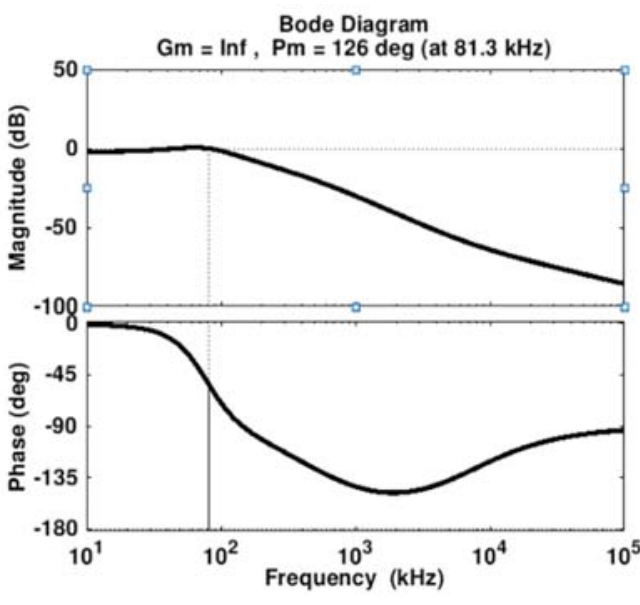

Figure 5. Bode of lead compensator

Bode plot of the designed lead compensator in Figure 5 having a phase compensation of 126degree at $81.3 \mathrm{kHz}$. 2. Lag compensator is used to improve the gain at lower frequency, hence output is regulated at dc.

$$
\mathrm{Gc}=\mathrm{Gco}\left(1+\frac{W l}{S}\right)
$$


This compensator will increase the dc loop gain, if the dc loop gain is very large, this causes the error of the dc component to zero, due to this steady state error can be regulated, and the disturbance-to-o/p transfer function approach zero at dc. Figure 6 shows simulink modal of the system with PID conntroller. Figure 7 shows bode of PID compensator. Figure 8 shows step response of the system after PID compensation. Figure 9 shows simulink modal of the system with PID compensator having PD out of forward path.

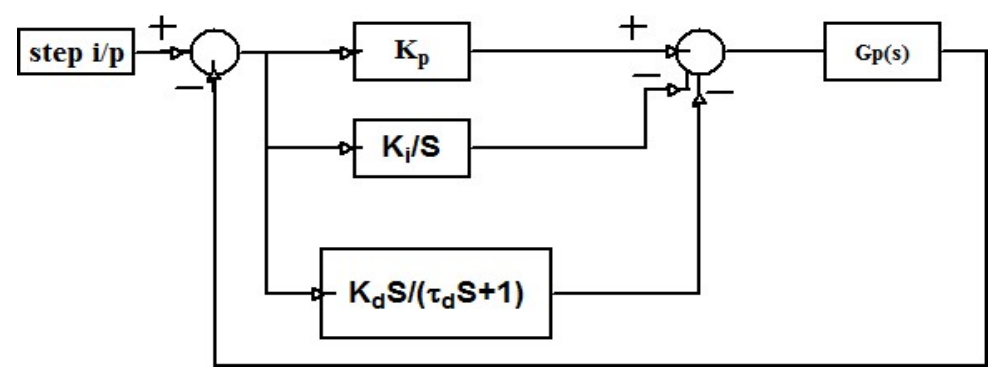

Figure 6. Simulink modal of the system with PID conntroller

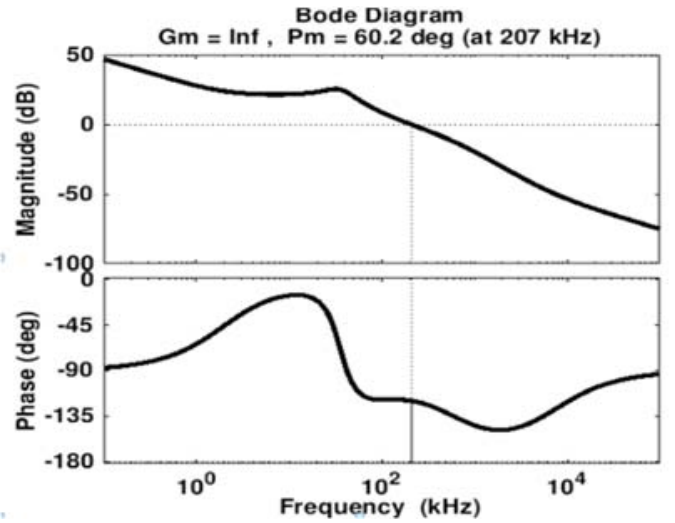

Figure 7. Bode of PID compensator

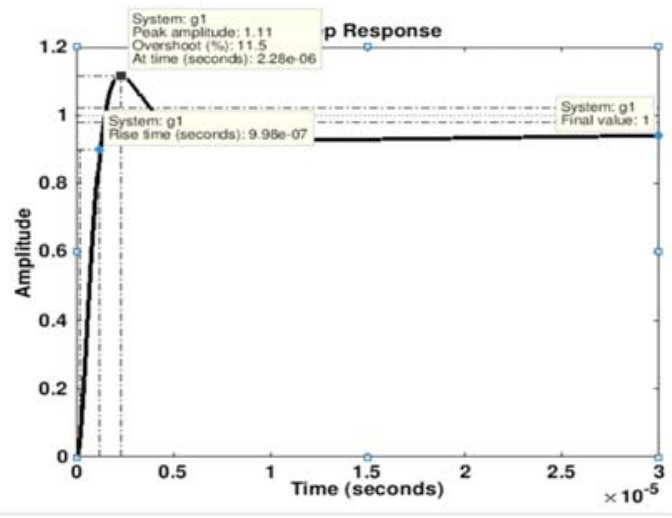

Figure 8. Step response of the system after PID compensation

$\% \mathrm{Mp}=11.5, \mathrm{tr}=9.98 e^{-7}, \mathrm{ess}=1$

If the PD controller in the forward path. when the reference input is step, which increase the overshoot, in improved PID controller derivative is out of the forward path which will decrease the overshot and rise time.

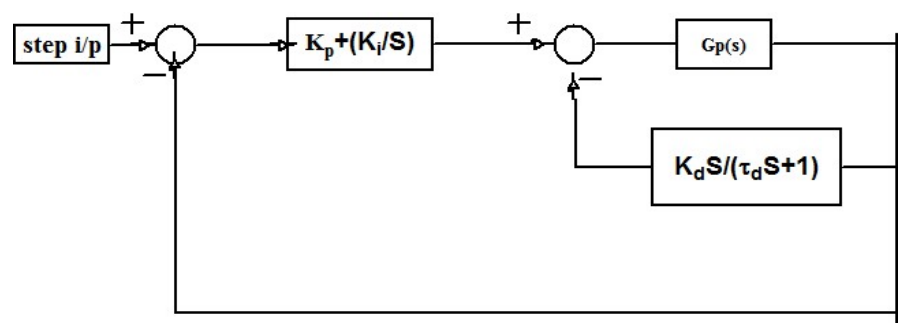

Figure 9. Simulink modal of the system with PID compensator having PD out of forward path 
Classical PID controller:

$$
G_{P I D}(s)=\frac{\left(K_{p} \tau_{d}+K_{d}\right) S^{2}+\left(K_{p}+\tau_{d} K_{i}\right) S+K_{i}}{\tau_{d} S^{2}+S}
$$

Where $\tau_{d}$ and $\tau_{i}$ are the integral and derivative times respectively, where $K_{p}, K_{d}$, and $K_{i}$ are the prapotional, derivative and integral constants, respectively. Designed lead-lag compensator:

$$
G_{c}(s)=\frac{\left(\frac{W_{Z}+S}{W_{Z}}\right)\left(\frac{S+W_{l}}{S}\right)}{\left(\frac{W_{p}+S}{W_{p}}\right)}
$$

Comparing the (20) and (21)

Designed values of the compensator:

$K_{p}=4.1033$

$K_{d}=6.42045 * 10^{-6}$

$K_{i}=397.386$ and

$\tau_{d}=2.6626 * 10^{-7}$

\subsection{Different configuration of the system}

Configuration 1: Figure 10 representing a MATLAB Simulink model of PID controlled buck converter. Transient response of the system after the PID compensation is $\% \mathrm{Mp}=11.5$, ts $=1.43 * 10^{-5}, \mathrm{tr}=9.9 * 10^{-6}$,ess $=1$. PID controller is added in the forward path to improve the transient and steady state error. PD is designed to improve the phase margin a zero is added to the loop gain at a frequency less than the switching frequency. PI and PD will increase the gain at lower and higher frequency respectively. Peak overshoot and rise time of the system is improved compared to the uncompensated system.

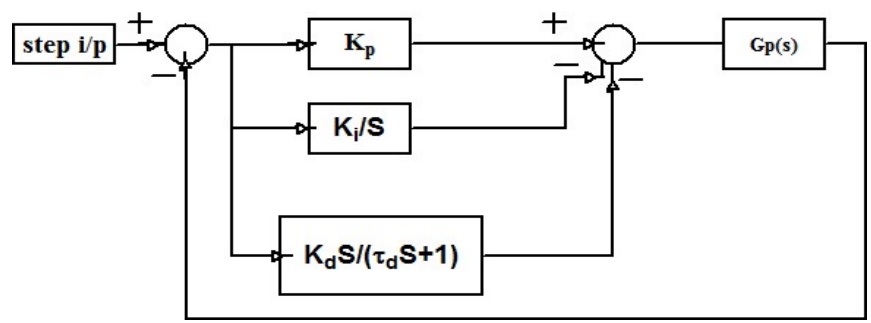

Figure 10. MATLAB simulink model of PID controlled buck converter

Configuration 2: Figure 11 represents the MATLAB Simulink model of PID -DOO Step response of the system after PID-DOO compensation is $\% \mathrm{Mp}=6.67, \mathrm{ts}=1.07 * 10^{-5}, \mathrm{tr}=1.93 * 10^{-6}$,ess $=1$.In PID-DOO configuration controller used is PID, But the connection of the PID is different, D is not added in the forward path, Because D in the forward path will affect the error signal. In in this configuration derivative action is only on the output signal.it will prevent the derivative part of the step input. Derivative of the input signal will increase the damping in the system which leads to increase in the peak overshoot and rise time.

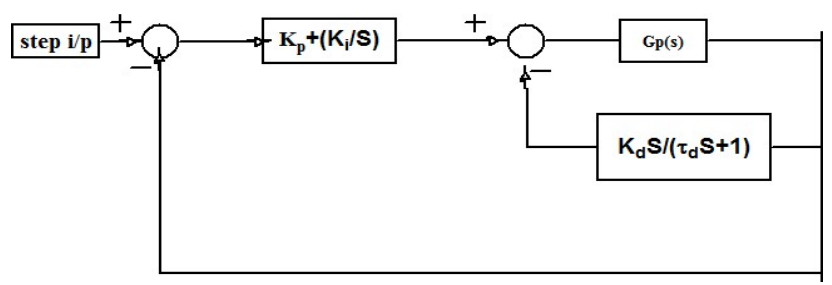

Figure 11. MATLAB simulink modal for PID-DOO controlled buck converter 
Configuration 3: Figure 12 shows the MATLAB Simulink model of the converter having PI in the forward path and PD after the impulse response. Step response of the system is $\% \mathrm{Mp}=51 \%, \mathrm{ts}=1.07 * 10^{-5}, \mathrm{tr}=1.93 * 10^{-6}, \mathrm{ess}=1$

In this configuration PI is placed in the forward path whereas PD is placed after the PI compensation along with the D will increase the gain of the at higher frequencies, and also PD will reduce the effect of the PI, Hence gain at lower frequencies will reduce leads to high damping. Hence peak over-shoot increase to higher value, this configuration is not suitable for the industrial applications.

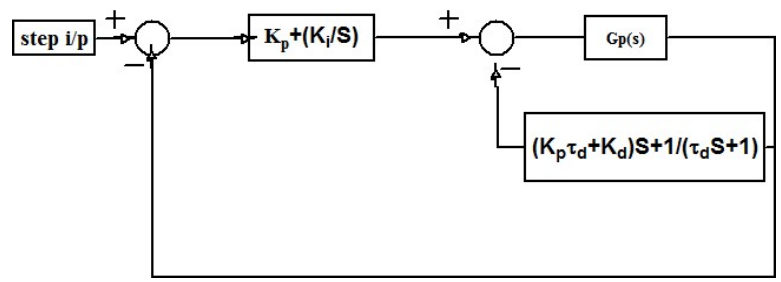

Figure 12. MATLAB simulink modal for PID controlled buck converter PI in forward path and $\mathrm{D}$ after the impluse response

Configuration 4: Figure 13 representing a MATLAB Simulink model of the converter with PD in the forward path and PI is placed after the impulse response of the system. Transient response of the converter is $\% \mathrm{Mp}=\mathrm{inf}, \mathrm{ts}=5.27 * 10^{-6}, \mathrm{tr}=0$,ess $=0$.In this configuration derivative is placed in forward path, it will differentiate the error signal, hence compensator effect on the error signal will be less. Gain at the higher frequencies is very less, which leads to high peak overshoot and rise time is zero. Peak overshoot is almost infinity this type of configuration cannot be used for any applications.

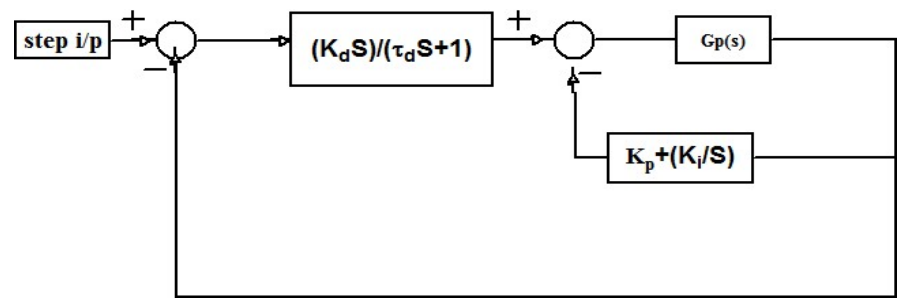

Figure 13. MATLAB simulink modal for PID controlled buck converter D in forward path and PI after the impluse response

Configuration 5: MATLAB Simulink model of the converter with $D$ in forward path and $P$ is placed after the impulse response of the system is shown in Figure 14, and transient response of the simulates MATLAB Simulink model is shown in Figure 15 with $\mathrm{Mp} \%=6.67, t_{s}=1.07 * 10^{-6}, t_{r}=1.92 * 10^{-6}, e_{s s}=0 . \mathrm{D}$ is placed in the forward path, which leads to reduction in peak overshoot and rise time is zero. Proportional controller increases the dc gain.

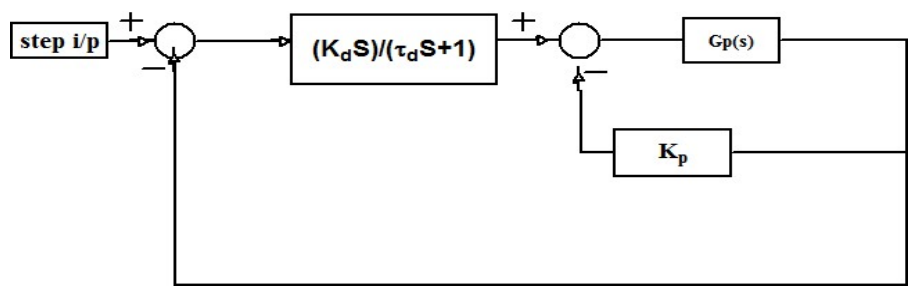

Figure 14. MATLAB simulink modal for PID controlled buck converter D in forward path and $\mathrm{P}$ after the impluse response 


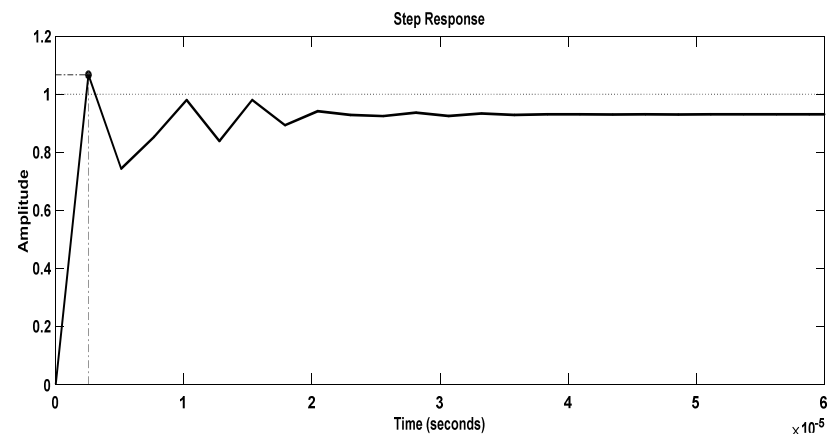

Figure 15. Step response of the system after PID compensation with PD out of forward path

While designing the compensator transient response of the system will be depend on the selection of the closed loop pole, pole is selected based on the transient specification requirement.

\section{RESULT ANALYSIS}

Comparing all the configurations shows that Configuration 2 is better for industrial applications. For any application, the peak overshoot should be within the limit. If it exceeds the limit value, disturbances in the system will increase leading to large settling time.

\section{CONCLUSION}

This paper systematically describes the design procedure for different controlling techniques based on bode plot. The derived PID controller shows the batter transient response compared to the uncompensated system, and how the derivative in the feedback loop will affect the transient response. Derivative in the feedback loop will introduce the impulse to the system which leads to the higher overshoot and rise time. Configuration 4 and 5 will shows the effect of the derivative in the forward path.

Comparing all the configurations, configuration two is better for the industrial applications. For any applications peak overshoot should be within the limit, if it exceeds the limit value disturbances in the system will increase, which leads to large settling time.

\section{REFERENCES}

[1] Chen Wang, Matthew Armstrong and Shady Gadoue, "System Identification and Adaptive Control of a DC-DC Converter using a Current Balancing ON/OFF Control Technique for Optimal Transient Performance", 17 European Conference on Power Electronics and Applications, pp.1-10,10 ${ }^{\text {th }}$ sept 2015.

[2] Zareh, Seiyed Hamid, Ali F. Jahromi, M. Abbasi, and Ali A. Khayyat, "The control of a thermal system with large time delay using of LQG and Lead-Compensator", IEEE International Conference on Mechatronics and Automation, pp. 1842 - 1847, 2010.

[3] Calderon, A.J., "Fractional order control strategies for power electronic buck converters," Signal Processing, 2006.

[4] R.M. Nelms and Liping Guo. "PID controller modifications to improve steady-state performance of digital controllers for buck and boost converters", APEC Seventeenth Annual IEEE Applied Power Electronics Conference and Exposition, vol.1, pp 381-388, 2002.

[5] Altinoz, O. Tolga and Hamit Erdem, "Particle swarm optimisation-based PID controller tuning for static power converters", Int. J. Power Electronics, Vol.7, Nos. 1/2, 2015.

[6] Hidenori Maruta, Hironobu Taniguchi, Yudai Furukawa and Fujio Kurokawa, "Improved Transient Response for Wide Input Range of DC-DC Converter with Neural Network Based Digital Controller", 19th European Conference on Power Electronics and Applications,pp.1-8, 2017.

[7] Robert W. Erickson, Dragan Maksimovic. "Fundamentals of Power Electronics", Springer Nature, 2001.

[8] Abhinav Dogra, Kanchan Pal., "Design of Buck-Boost Converter for Constant Voltage Applications and Its Transient Response Due To Parametric Variation of PI Controller", International Journal of Innovative Research in Science, Engineering and Technology, Vol.3, pp-13579-13588, june 2014.

[9] Ghulam Abbas and Umar Farooq, “An Improved PID Controller for Switching Converters",11th World Congress on Intelligent Control and Automation Shenyang, pp.1445 - 1450, July 4th, 2015.

[10] Wies, Richard, BipinSatavalekar, Ashish Agrawal, JavadMahdavi, Ali Agah, Ali Emadi, and Daniel Jeffrey Shortt. "DC-DC Converters", Industrial Electronics, 2001.

[11] K. Ogata, "Modern Control Engineering," Prentice-Hall, 5th Edition, NJ, 2010.

Int J Pow Elec \& Dri Syst, Vol. 10, No. 1, March 2019: 256 - 264 